\title{
Profil Kondisi Fisik dan Motif Berprestasi Pada Siswa Ekstrakurikuler Sepakbola
}

\section{Physical Profile and Achievment Motivation of Football Extracurricular Activities in Senior High School Students}

\author{
Kartono Pramdhan'1, Rizki Nurdianto², Gugun Gunawan² \\ 1,2,3Program Studi PJKR, Sekolah Tinggi Keguruan IImu dan Pendidikan (STKIP) Pasundan Kota \\ Cimahi, Indonesia \\ email: kartonopramdhan.04@gmail.com¹, rizky10@gmail.com², gunyat123@yahoo.com³
}

doi): $\underline{\text { htps://doi.org/10.20884/1.paju.2021.2.2.3798 }}$

\begin{abstract}
Abstrak
Sepakbola merupakan olahraga permainan yang perlu ditunjang dengan kondisi fisik yang baik, selain itu motif berprestasi juga merupakan aspek penting lainnya yang perlu dimiliki oleh setiap pemain sepakbola. Penelitian ini bertujuan untuk mengungkapkan profil kondisi fisik dan motif berprestasi pada siswa ektrakurikuler sepakbola. Penelitian ini menggunakan penelitian deskriptif kualitatif. Sampel yang digunakan adalah siswa yang mengikuti ekrakurikuler sepakbola di Sekolah Menengah Atas Negeri Serangpanjang dengan jumlah 25 siswa. Teknik pengumpulan data dalam penelitian ini dilakukan dengan cara tes kondisi fisik dan pengisian angket motif berprestasi. Hasil penelitian menunjukan bahwa profil kondisi fisik siswa yang mengikuti ektrakurikuler sepakbola di SMAN 1 Serangpanjang berada pada kategori sedang. Hasil pengisian angket motif berprestasi menunjukan siswa dalam kategori kurang sekali $0 \%$, kurang $0 \%$, sedang $0 \%$, baik $80 \%$ dan baik sekali $20 \%$. Maka dapat disimpulkan bahwa motif berprestasi siswa ektrakurikuler sepakbola SMAN 1 Serangpanjang pada kategori baik dengan $80 \%$. Rekomendasi dari penelitian ini yaitu siswa ektrakurikuler sepakbola perlu meningkatkan kondisi fisik melalui latihan, serta dapat mempertahankan motif berprestasi sebagai dasar untuk setiap siswa meningkatkan hasil latihan dan dapat menunjang dalam pencapaian prestasi sepakbola di tingkat pelajar.
\end{abstract}

Kata Kunci : Profil, Kondisi Fisik, Motif Berprestasi, Sepakbola

\begin{abstract}
Football is a sport that needs to be supported by a good physical condition. Besides that, the motive for achievement is also another important aspect that every football player should have. This study aims to reveal the profile of the physical condition and achievement motives of the football extracurricular students. This research uses descriptive qualitative research. The sample used was 25 students who took part in the extracurricular football at the State Senior High School in Serangpanjang. Data collection techniques in this study were carried out by means of tests of physical conditions and filling out a
\end{abstract}

Alamat Koresponden: Program Studi PJKR, Sekolah Tinggi Keguruan IImu dan Pendidikan (STKIP) Pasundan Kota Cimahi, Indonesia

Email : kartonopramdhan.04@gmail.com (c) (i) 
questionnaire of achievement motives. The results showed that the physical condition profile of students who took the extracurricular football at SMAN 1 Serangpanjang was in the medium category. The results of filling out the achievement motive questionnaire showed that the students were in the category of very low $0 \%$, less $0 \%$, moderate $0 \%$, good $80 \%$ and very good $20 \%$. So it can be concluded that the extracurricular achievement motive for the football extracurricular activities at SMAN 1 Serangpanjang is in the good category with $80 \%$. The recommendation of this research is that football extracurricular students need to improve their physical condition through training, and be able to maintain their achievement motive as the basis for each student to improve their training results and can support the achievement of soccer achievement at the student level.

Keywords : Profile, Physical Condition, Motives for Achievement, Football

\section{PENDAHULUAN}

Olahraga pada perkembangannya telah menjadi sarana rekreasi, pendidikan, prestasi, dan kesehatan. Olahraga dalam ranah pendidikan dilaksanakan pada lingkungan sekolah dengan tujuan untuk mengembangkan potensi yang dimiliki oleh siswa. Tujuan pendidikan jasmani yaitu untuk mengembangkan aspek pengetahuan, sikap dam keterampilan gerak pada siswa, sehingga siswa dapat berkembang dengan baik (Budi, Hidayat, \& Febriani, 2019; Rahayu, Subroto, \& Budiman, 2020)

Pendidikan jasmani adalah proses pendidikan melalui pendekatan belajar siswa berupa aktivitas jasmani, bermain, dan berolahraga yang direncanakan secara sistematik guna merangsang pertumbuhan dan perkembangan fisik, keterampilan motorik, keterampilan berfikir, emosional sosial dan moral (Nur et al., 2020; Suherman, 2009). Berdasarkan pendapat tersebut maka program pembelajaran pendidikan jasmani menjadi bagian penting dalam membantu perkembangan siswa. Salah satu materi pembelajaran yang diajarkan kepada siswa adalah olahraga permainan sepakbola.

Pada hakikatnya sepakbola merupakan permainan beregu yang menggunakan bola sepak. Sepakbola dimainkan di lapangan rumput oleh dua regu yang saling berhadapan dengan masing-masing regu terdiri dari sebelas pemain (Bennike, Wikman, \& Ottesen, 2014; Syafi'i \& Setiawan, 2019). Tujuan permainan ini dimainkan adalah untuk memasukkan bola ke gawang lawan sebanyak-banyaknya dan berusaha mempertahankan gawang sendiri dari serangan lawan (Danurwindo \& Barry, 2014). Ada pun karakteristik yang menjadi ciri khas permainan ini adalah memainkan bola dengan menggunakan seluruh anggota tubuh kecuali lengan. Sepakbola adalah suatu permainan yang dilakukan 
Kartono Pramdhan, Rizki Nurdianto \& Gugun Gunawan | Profil Kondisi Fisik dan Motif Berprestasi Siswa Yang Mengikuti Ekstrakurikuler Sepakbola

dengan cara menendang bola, yang mempunyai tujuan untuk memasukkan bola ke gawang lawan dengan mempertahankan gawang tersebut agar tidak kemasukan bola (Kavcic, Milic, Jourkesh, Ostojic, \& Ozkol, 2012).

Olahraga sepkabola pada tingkat sekolah diajarkan dalam dua jenis kegiatan yaitu, intrakurikuler dan ekstakurikuler (Qohhar \& Pazriansyah, 2019). Lebih lanjut dalam UU SKN (2005) dijelaskan bahwa ekstrakurikuler olahraga merupakan wadah bagi siswa untuk mengembangkan bakat yang dimiliki dan mencapai prestasi. Sepakbola pada kegiatan ekstrakurikuler merupakan salah satu bentuk pembinaan olahraga bagi siswa untuk dapat mencapai prestasi, melalui berbagai kejuaraan tingkat pelajar.

Olahraga prestasi adalah olahraga yang membina dan mengembangkan olahragawan secara terencana, berjenjang dan berkelanjutan melalui kompetensi untuk mencapai prestasi tinggi dengan dukungan ilmu pengetahuan dan teknologi keolahragaan (Satriya, Dikdik, \& Imanudin, 2013). Sesuai dengan pengertian olahraga prestasi tersebut diatas, maka olahraga prestasi merupakan olahraga pembinaan dan pengembangan potensi dalam diri seseorang yang dilakukan secara terencana, berjenjang dan melalui kopetensi dengan tujuan untuk meraih prestasi tinggi.

Dalam melakukan aktivitas olahraga seseorang juga harus memiliki kondisi fisik yang baik sehingga mampu melakukan aktivitas olahraga yang dilakukannya tanpa mengalami kelelahan yang berlebihan. Apabila seseorang memiliki kondisi fisik yang kurang baik apalagi buruk maka seseorang akan kesulitan dalam melakukan aktivitas olahraga tersebut sehingga menyebabkan kelelahan yang berlebihan. Seorang pemain sepakbola dapat melakukan berbagai teknik dasar dan bermain sepakbola dengan baik apabila memiliki kondisi fisik yang prima. Hasil penelitian menunjukan bahwa kondisi fisik menjadi faktor penting dalam olahraga permainan, sehingga perlu dibina dan ditingkatkan (Hidayat et al., 2020; Saepuloh \& Pramdhan, 2017).

Selain kondisi fisik, seorang pemain sepakbola khusnya pada tingkat pelajar perlu memiliki motivasi dalam berlatih sehingga dapat meningkatkan keinginan untuk mencapai prestasi sebagai pesepakbola. Motivasi menjadi bagian penting bagi seorang atlet sepakbola pelajar. Hasil penelitian menunjukan bahwa atlet pelajar dengan motivasi dan percaya diri yang baik dapat mengembangkan keterampilan dan teknik permainan dengan lebih baik (Efendi, 2016; Kamnuron et al., 2020; Muskanan, 2015). 
Dari hasil observasi peneliti di SMAN 1 Serangpanjang siswa peserta ekstrakurikuler sepakbola ketika latihan jarang hadir, akan tetapi ketika sekolah akan mengikuti sebuah pertandingan tingkat kehadiran siswa meningkat. Informasi ini didapat dari pelatih dan guru pendidikan jasmani disekolah tersebut. Motivasi berprestasi olahraga merupakan tujuan yang dimiliki atlet untuk berprestasi, dengan begitu atlet akan berusaha meningkatkan berbagai usaha dan gigih dalam latihan agar dapat berprestasi untuk mendapatkan berbagai penghargaan yang dapat meningkatkan harga dirinya (Apriansyah, Sulaiman, \& Mukarromah, 2017; Padmowihardjo, 2014).

Hasil observasi lain juga menunjukan bahwa pada saat pertandingan uji coba terlihat siswa seperti kurang motivasi dalam bermain untuk menunjukan hasil latihan, yang terlihat di lapangan mereka mudah menyerah ketika dalam keadaan tim tertinggal dan kalah dalam penguasaan bola. Dalam kasus ini, siswa kurang memiliki motivasi juang yang tinggi. Peran motivasi adalah sebagai pemasok daya (energizer) untuk tingkah laku secara terarah, motivasi berprestasi merupakan ciri seorang yang mempunyai harapan tinggi untuk mencapai keberhasilan dari pada ketakutan kegagalan (Komarudin, 2010; Sumarjo, 2017).

Kasus lain yang ditemukan pada siswa ektrakurikuler sepakbola di SMAN 1 Serangpanjang yaitu dalam sebuah pertandingan uji coba dengan sekolah lain terlihat pada 15 menit awal akurasi passing masih baik dan mencapai sasaran, akan tetapi ketika 15 menit selanjutnya perlahan pemain seperti kelelahan sehingga menyebabkan mengurangi akurasi ketepatan passing dan shooting mereka. Mereka cenderung bermain kasar karena faktor kelelahan dan kurang konsentrasi, sehingga hal tersebut belum menunjukan motivasi berprestasi yang tinggi untuk menunjukan permainan yang baik dan memenangkan pertandingan.

Berdasarkan hasil observsi dan permasalahan yang terjadi dilapangan tersebut peneliti menduga kondisi fisik dan motivasi yang dimiliki oleh atlet belum sesuai dengan harapan yang diinginkan. Apabila hal ini terus dibiarkan akan mempengaruhi pencapaian prestasi maksimal. Oleh sebab itu, perlu dibuktikan secara ilmiah, melalui sebuah penelitian mengenai Profil Kondisi Fisik dan Motif Berprestasi Siswa Ektrakurikuler Sepakbola di SMAN 1 Serangpanjang. 
Kartono Pramdhan, Rizki Nurdianto \& Gugun Gunawan | Profil Kondisi Fisik dan Motif Berprestasi Siswa Yang Mengikuti Ekstrakurikuler Sepakbola

\section{METODE}

Metode yang digunakan dalam penelitian ini adalah metode deskriptif kuantitatif. Metode deskriptif kuantitatif adalah penelitian yang dilakukan untuk mengetahui keberadaan nilai variabel mandiri, baik satu variabel atau lebih (independent) tanpa membuat perbandingan atau menghubungkan dengan variabel lain (Sugiyono, 2016). Tujuan penelitian ini adalah sebagai berikut: 1) Untuk mengetahui berada pada kategori manakah kondisi fisik siswa yang mengikuti ektrakurikuler sepakbola. 2) Untuk mengetahui bagaimanakah motif berprestasi siswa yang mengikuti ektrakurikuler sepakbola. Peneltian ini dilakukan di ektrakurikuler sepakbola SMAN 1 Serangpanjang. Waktu penelitian dilakukan selama bulan Februari-Maret 2020.

Sampel dalam penelitian ini adalah 25 siswa peserta ektrakurikuler. Teknik pengambilan sampel pada penelitian ini yaitu menggunakan total sampling. Instrument dalam penelitian ini menggunakan angket motif berprestasi dan Bleep Test, Tes kelincahan Arrow Head Agility Drill, Vertical Jump, Push Up, Sit Up, Tes Sprint, Data yang diambil dari hasil pengukuran, kemudian diolah secara statistik dengan menggunakan Penilaian Acuan Patokan (PAP).

\section{HASIL}

Berikut ini adalah hasil tes kondisi fisik yang dimiliki oleh siswa ekstrakurikuler sepakbola di SMAN 1 Serangpanjang, dapat dilihat pada tabel 1. dibawah ini.

Tabel 1. Hasil Tes Kondisi Fisik Siswa Ektrakurikuler Sepakbola

\begin{tabular}{lccc}
\hline Tes Fisik & Rata-Rata Hasil Tes & \multicolumn{2}{c}{ Kategori } \\
\hline Push Up & 32 & 4 & Baik \\
\hline Sit Up & 42 & 4 & Baik \\
\hline Back Up & 39 & 4 & Baik \\
\hline Half Squat & 40 & 4 & Baik \\
\hline Vertical Jump & 38 & 2 & Kurang \\
\hline Sprint & 4.3 & 4 & Baik \\
\hline Arrowhead Agility Test & 16.8 & 3 & Sedang \\
\hline Daya Tahan (Bleep Test) & 34 & 3 & Sedang \\
\hline Rata-Rata Tes Fisik & & 3.5 & Sedang \\
\hline
\end{tabular}

Berdasarkan hasil tes kondisi fisik yang telah dilaksanakan di ektrakurikuler sepakbola SMAN 1 Serangpanjang yang telah melalui tes dan pengukuran maka dapat 
disimpulkan bahwa kondisi fisik siswa peserta ektrakurikuler SMAN 1 Serang panjang berada pada kategori sedang.

Berikutnya yaitu tingkat motif berprestasi berdasarkan hasil angket yang telah diberikan kepada siswa ektrakurikuler sepakbola SMAN 1 Serang panjang mendapatkan hasil seperti tertera pada tabel 2. dibawah ini.

Tabel 2. Motivasi Berprestasi Siswa Ektrakurikuler Sepakbola

\begin{tabular}{ccc}
\hline Kategori & Jumlah & Prosentase (\%) \\
\hline Baik Sekali & 5 & 20 \\
\hline Baik & 20 & 80 \\
\hline Sedang & 0 & 0 \\
\hline Kurang & 0 & 0 \\
\hline Kurang Sekali & 0 & 0 \\
\hline
\end{tabular}

Berdasarkan tabel diatas dapat dideskripsikan bahwa motivasi berptestasi dengan kategori Baik sekali sebanyak 5 orang atau sebesar 20\%, Baik sebanyak 20 orang atau $80 \%$ dan tidak ada siswa yang berada pada kategori motivasi berprestasi Sedang, Kurang seta Kurang Sekali. Maka dapat disimpulkan bahwa motif berprestasi siswa ektrakurikuler Sepak Bola SMAN 1 Serangpanjang pada kategori baik dengan $80 \%$.

\section{PEMBAHASAN}

Hasil penelitian menunjukan bahwa kondisi fisik siswa ektrakurikuler sepakbola di SMAN 1 Serangpanjang rata-rata dalam kondisi sedang. Hal ini dikarenakan hampir sebagian besar siswa tidak menjalankan program ektrakurikuler dengan baik, dalam pelaksanaan latihan banyak siswa yang tidak hadir. Hasil penelitian ini sesuai dengan penelitian terdahulu bahwa kondisi fisik keseluruhan pemain sepakbola SMA Negeri 1 Kabupaten Kaur adalah kurang (Azidman, 2017).

Kondisi fisik yang baik akan berpengaruh terhadap fungsi dan sistem organ tubuh pada saat berolahraga. Kemampuan fisik adalah kemampuan memfungsikan organ-organ tubuh dalam melakukan aktivitas fisik (Saepuloh \& Pramdhan, 2017). Berdasarkan hal tersebut maka kemampuan atau kondisi fisik sangat penting untuk mendukung dalam melakukan berbagai keterampilan teknik bermain sepakbola. 
Kartono Pramdhan, Rizki Nurdianto \& Gugun Gunawan | Profil Kondisi Fisik dan Motif Berprestasi Siswa Yang Mengikuti Ekstrakurikuler Sepakbola

Alasan utama pentingnya kondisi fisik yang baik perlu dimiliki oleh pemain sepakbiola yaitu karena karakteristik permainan sepakbola dimainkan dalam waktu yang lama, menggunakan lapangan yang luas, pola permainan yang saling serang dan bertahan serta melakukan berbagai macam teknik permainan sepakbola. Hasil penelitian menunjukan bahwa pemain sepakbola dengan kondisi fisik yang baik dapat melakukan berbagai keterampilan dengan lebih baik dibandingkan dengan pemain dengan kondisi fisik kurang (Anwar, 2013; Prasetya \& Hariadi, 2018)

Selaian kondisi fisik, faktor motif berprestasi juga menjadi salah satu faktor penting dalam menunjang peningkatan prestasi pada atlet sepakbola, khususnya di tingkat pelajar. Hasil penelitian menunjukan bahwa siswa ektrakurikuler di SMAN 1 Serangpanjang memiliki motif berprestasi dengan kategori baik. Hasil tersebut merupakan modal yang baik bagi keberlangsungan kegiatan ektrakurikuler sepakbola di sekolah. Siswa dengan motif berprestasi baik pada perkembangannya dapat meningkatkan kondisi fisik dan keterampilan bermain sepakbola.

Hasil penelitian terdahulu menunjukan bahwa motivasi berprestasi dapat meningkatkan keinginan siswa untuk berlatih dan meningkatkan kondisi fisik serta prestasi dalam olahraga (Wahyudi, 2019; Zulkarnain \& Haqiyah, 2018). Hasil penelitian tersebut menunjukan bahwa dengan motivasi, pemain sepakbola dapat mengembangkan dirinya dengan lebih baik dari segi kondisi fisik maupun teknik permainan.

Kombinasi antara kondisi fisik dan motif berprestasi yang dimiliki oleh siswa menjadi komponen penting dalam pengembangan prestasi sepakbola di tingkat sekolah. Berdasarkan hal tersebut maka penting bagi pelatih dan pembina ekstrakurikuler sepakbola di sekolah untuk menerapkan program latihan kondisi fisik dan pelatihan mental pada atlet selain program latihan teknik dan taktik permainan sepakbola.

\section{SIMPULAN}

Berdasarkan hasil tes kondisi fisik yang telah dilaksanakan di ekstrakurikuler sepakbola SMAN 1 Serang panjang yang telah melalui tes dan pengukuran maka dapat disimpulkan bahwa kondisi fisik siswa peserta ektrakurikuler di SMAN 1 Serang panjang berada pada kategori sedang, sedangkan untuk motif berprestasi yang dimiliki siswa menunjukan hasil berada pada kategori baik. Saran dari penelitian ini yaitu siswa ekstrakurikuler sepakbola perlu meningkatkan kondisi fisik melalui latihan, serta dapat 
mempertahankan motif berprestasi sebagai dasar untuk setiap siswa meningkatkan hasil latihan dan dapat menunjang dalam pencapain prestasi sepakbola di tingkat pelajar. Rekomendasi untuk penelitian selanjutnya dapat mengkaji mengenai aspek psikologi yang berbeda pada siswa ekstrakurikuler sepakbola dan dapat dikaitkan dengan penguasaan keterampilan teknik dasar maupun bermain sepakbola.

\section{REFERENSI}

Anwar, S. (2013). Survei Teknik Dasar Dan Kondisi Fisik Pada Siswa Sekolah Sepak Bola (Ssb) Se Kabupaten Demak Tahun 2012. Active - Journal of Physical Education, Sport, Health and Recreation, 2(9), 596-604. https://doi.org/10.15294/active.v2i9.1861

Apriansyah, B., Sulaiman, \& Mukarromah, S. B. (2017). Kontribusi Motivasi, Kerjasama, Kepercayaan Diri terhadap Prestasi Atlet Sekolah Sepakbola Pati Training Center di Kabupaten Pati. Journal of Physical Education and Sports.

Azidman, L. (2017). Profil Kondisi Fisik Pemain Sepak Bola Sma Negeri 1 Kaur. Kinestetik: Jurnal IImiah Pendidikan Jasmani, 1(1).

Bennike, S., Wikman, J. M., \& Ottesen, L. S. (2014). Football Fitness - A New Vesion of Football A Concept for Adult Players in Danish Football Clubs. Denmark: Scandinavian Journal of Medicine \& Science in Sport Volume 24 Number 1.

Budi, D. R., Hidayat, R., \& Febriani, A. R. (2019). The Application of Tactical Approaches in Learning Handballs. JUARA: Jurnal Olahraga. https://doi.org/10.33222/juara.v4i2.534

Danurwindo, P. G., \& Barry, S. (2014). Kurikulum Pembinaan Sepakbola Indonesia. Jakarta: Menara Mandiri.

Efendi, R. (2016). Pengaruh Metode Latihan Practice Session, Test Session Dan Motivasi Berprestasi Terhadap Keterampilan Menendang Dalam Sepak Bola. Jurnal Pendidikan UNSIKA, 4(1), 91-106.

Hidayat, R., Budi, D. R., Purnamasari, A. D., Febriani, A. R., \& Listiandi, A. D. (2020). Faktor Fisik Dominan Penentu Keterampilan Bermain Sepak Takraw. Jurnal MensSana. https://doi.org/10.24036/jm.v5i1.127

Kamnuron, A., Hidayat, Y., \& Nuryadi, N. (2020). Perbedaan Kepercayaan Diri Pada Siswa yang Mengikuti Ekstrakurikuler Olahraga. Physical Activity Journal. https://doi.org/10.20884/1.paju.2020.1.2.2394

Kavcic, I., Milic, R., Jourkesh, M., Ostojic, S. M., \& Ozkol, M. Z. (2012). Comparative study of measured and predicted vo 2 maxduring a multi-stage fitness test with junior soccer players. Kinesiology. 
Kartono Pramdhan, Rizki Nurdianto \& Gugun Gunawan | Profil Kondisi Fisik dan Motif Berprestasi Siswa Yang Mengikuti Ekstrakurikuler Sepakbola

Komarudin. (2010). Penerapan Psikologi Dalam Meningkatkan Penampilan Atlet. Jurnal Kepelatihan Olahraga.

Muskanan, K. (2015). Analisis Motivasi Berprestasi Atlet Pusat Pendidikan dan Latihan Olahraga Pelajar Provinsi Nusa Tenggara Timur. JKAP (Jurnal Kebijakan Dan Administrasi Publik). https://doi.org/10.22146/jkap.7608

Nur, L., Malik, A. A., Juditya, S., Kastrena, E., Widyawan, D., Agustan, B., ... Yang, C. B. (2020). Comparison of two types of instruction in physical education. International Journal of Psychosocial Rehabilitation, 24(10), 1785-1793. https://doi.org/10.37200/IJPR/V24I10/PR300205

Padmowihardjo, S. (2014). Psikologi Belajar Mengajar. Pengertian Psikologi Belajar Mengajar Dan Definisi Proses Belajar.

Prasetya, Y., \& Hariadi, Y. I. (2018). Profil Kondisi Fisik Atlet Persatuan Sepak Bola Malang U-17 (Persema). Indonesia Performance Journal, 2(2), 105-110.

Qohhar, W., \& Pazriansyah, D. (2019). Pengaruh Model Pembelajaran Kooperatif Tipe Teaching Games For Understanding (TGFU) Terhadap Peningkatan Hasil Belajar Teknik Dasar Sepakbola. Physical Activity Journal. https://doi.org/10.20884/1.paju.2019.1.1.1998

Rahayu, R., Subroto, T., \& Budiman, D. (2020). Implementasi Model Pembelajaran Pada Olahraga Permainan Bolatangan. Physical Activity Journal. https://doi.org/10.20884/1.paju.2020.1.2.2172

Saepuloh, E., \& Pramdhan, K. (2017). Tingkat Kondisi Fisik Tim Nasional Floorball pada Kejuaraan Asia Oceania Floorball Competition (AOFC). Jurnal Olahraga. https://doi.org/10.37742/jo.v3i2.76

Satriya, Dikdik, \& Imanudin. (2013). Teori Latihan Olahraga (2014th ed.; R. U. Setria, Ed.). Bandung.

Sugiyono. (2016). Memahami Penelitian Kualitatif. Bandung: Alfabeta.

Suherman, A. (2009). Revitalisasi Pengajaran dalam Pendidikan Jasmani. Bandung: CV. Bintang Warli Artika.

Sumarjo. (2017). Peran Psikologi Olahraga Dan Kepelatihan Dalam Olahraga. Journal Warta.

Syafi'i, I., \& Setiawan, A. (2019). Koordinasi Mata Dan Kaki Pada Long Passing Sepak Bola. Physical Activity Journal. https://doi.org/10.20884/1.paju.2019.1.1.1993 
UU SKN. (2005). Undang-Undang Republik Indonesia Nomor 3 Tahun 2005. Jakarta: Republik Indonesia.

Wahyudi, D. (2019). Motivasi Berprestasi Atlet Sepakbola Jordus FC Kota Batusangkar. Jurnal Pendidikan Dan Olahraga, 2(1), 126-130.

Zulkarnain, F., \& Haqiyah, A. (2018). Pengaruh Metode Latihan dan Motivasi Berprestasi Terhadap Keterampilan Menggiring Bola. Perspektif IImu Pendidikan, 32(1), 17-23. 